\title{
Peatland ecosystem services during the Anthropocene and beyond
}

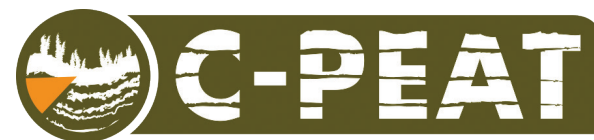

\author{
Angela V. Gallego-Sala', J. Loisel ${ }^{2}$ and M. Garneau \\ University of Exeter, UK, 1-4 May 2019
}

Members of the C-PEAT working group (pastglobalchanges.org/c-peat) met at Exeter University for the first meeting of Phase II of the working group. The aim of the workshop (pastglobalchanges.org/calendar/2019/127pages/1937) was to discuss the more recent (post-industrial) role of peatlands in the carbon cycle and the ecosystem services (ES) they have provided and will continue to provide in the future.

In our planning meeting in Texas last year, the C-PEAT scientific committee highlighted the need to predict peatland responses to anthropogenic disturbances, so integrating human impacts on ecosystem functioning was integral to this workshop. The discussion was divided into two topics/days: 1) carbon cycling in peatlands since the Industrial Revolution and 2) other ES provided during this period. Workshop participants included not only the habitual peat paleo community but, in addition, we invited peatland flux scientists, peat modelers, peatland stakeholders and ES experts, including several tropical peatland experts. Bringing different expertise into the same room allowed for interesting presentations, group discussions and brainstorming exercises (Fig. 1).

\section{Carbon cycling in peatlands}

Under this heading the community worked towards bringing together ongoing efforts to gather regional, national and global databases of the recent carbon accumulation records in peatlands. The brainstorming work focused on many topics including: 1) developing a better analysis of this part of the record to tease out allogenic versus auto genic drivers of carbon accumulation, 2) locating the carbon accumulation hotspots on a global scale, and developing a peatland health index based on existing peat carbon data syntheses, 3) identifying the changes in radiative forcing of peatlands driven by recent changes using regions with high data density (Canada and Fennoscandia), and 4) exploring the economic impacts of the carbon sink loss brought about by anthropogenic impacts. The meeting produced many ideas for future work and direction of research within the community, including the preparation of at least two community manuscripts that will present key results from the aforementioned research objectives.

\section{Other peatland ecosystem services provision}

We discussed current and future peatland $E S$, including ongoing restoration efforts

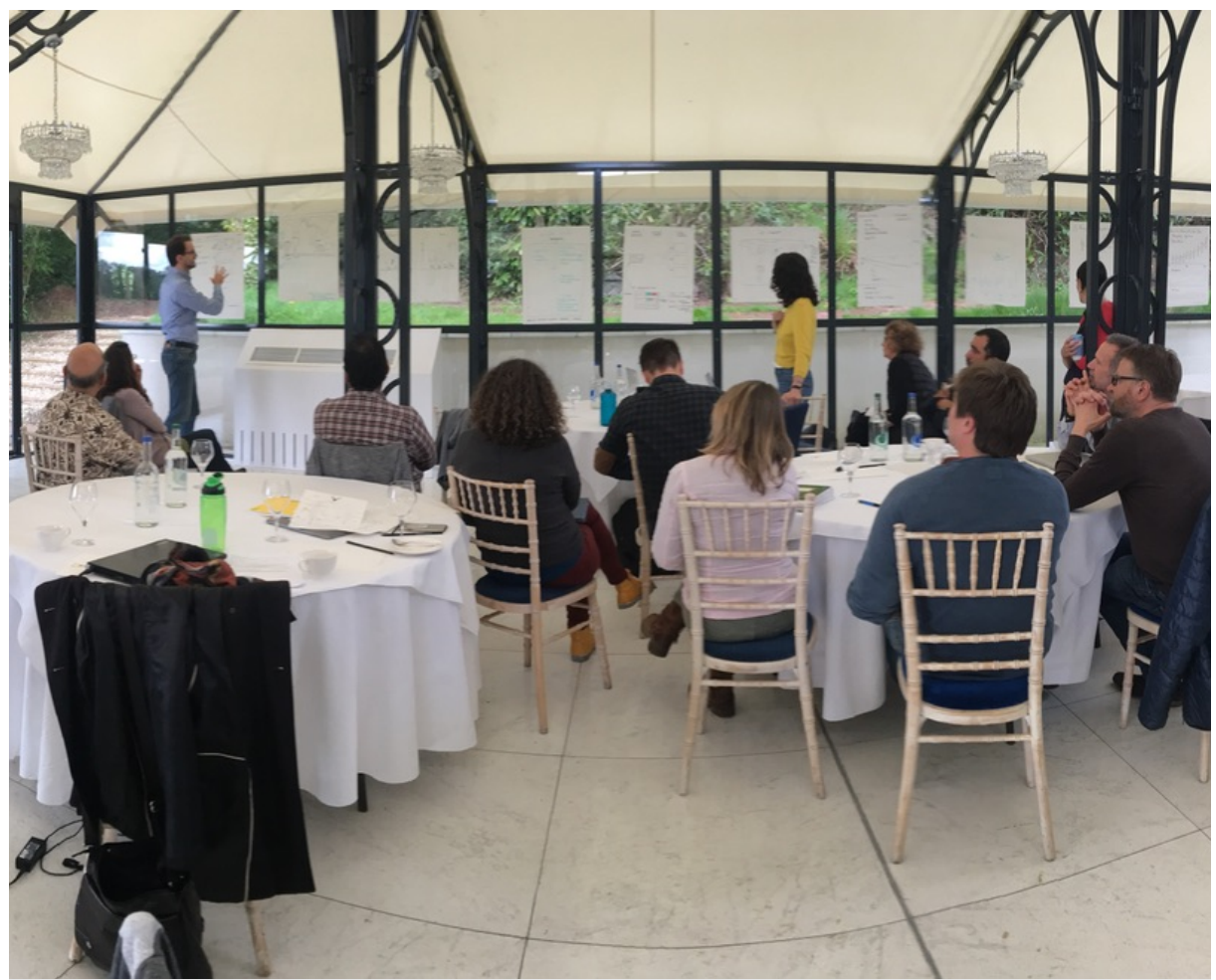

and loss of ES in different areas around the globe. In particular, we discussed what the paleo record may tell us about the changes in ES since the Industrial Revolution and how it may inform predictions of future trajectories of ES. Besides carbon regulation, workshop participants identified a suite of $E S$ and their relative importance across different regions of the world. For example, while Andean peatlands are most significant for water provision and regulation, those from the Indonesian lowlands matter most in terms of their food provisioning, biodiversity hotspot and climate change mitigation capacity (Law et al. 2015). We also explored how the C-PEAT paleo peat community may inform management of these important ecosystems and planned two outcomes that represent our first steps in working more closely with practitioners and other stakeholders: 1) policy briefing note - the community will produce a note for policymakers highlighting the main drivers of carbon accumulation of peatlands to help them make better decisions to improve ecosystem management; 2) Marie Skłodowska-Curie Innovative Training Network - the community will apply for a EU-funded training network in January 2021 using contacts with stakeholders to strengthen the application.

\section{Next steps}

One of the next steps for C-PEAT is to better integrate tropical and extra-tropical peatlands in the databases, an attempt already started in one of the latest community papers (Gallego-Sala et al. 2018). To achieve this, our next meeting will be held in May 2020 in Bangkok, Thailand, with a focus on tropical peatlands.

\section{ACKNOWLEDGEMENTS}

We thank PAGES, INQUA, NSF, and the College of Life and Environmental Sciences at the University of Exeter for financial and logistical support.

\section{AFFILIATIONS}

'Department of Geography, College of Life and Environmental Sciences, University of Exeter, UK ${ }^{2}$ Department of Geography, Texas A\&M University, College Station, USA

${ }^{3}$ Department of Geography and Geotop, Université de Québec à Montréal, Canada

\section{CONTACT}

Angela Gallego-Sala: a.gallego-sala@exeter.ac.uk

REFERENCES

Gallego-Sala AV et al. (2018) Nat Clim Change 8: $907-913$ Law EA et al. (2015) Ecol Appl 25: 70-87

Figure 1: Discussion session after brainstorming during the C-PEAT workshop in Devon. 